\title{
O DESENVOLVIMENTO REGIONAL COMO PROCESSO DE ENCADEAMENTO DE DINÂMICAS ORGANIZATIVAS E TRAJETÓRIAS TECNOLÓGICAS: O CASO DA REGIÃO OESTE CATARINENSE
}

\author{
REGIONAL DEVELOPMENT AS A CHAIN PROCESS OF \\ ORGANIZATIONAL DYNAMICS AND TECHNOLOGICAL \\ ROUTES: THE CASE OF SANTA CATARINA'S WESTERN \\ REGION
}

\author{
Bianca Cristina Aléssio \\ Universidade Comunitária Regional de Chapecó - SC - Brasil \\ Oscar José Rover \\ Universidade Federal de Santa Catarina - SC - Brasil
}

\begin{abstract}
Resumo: As últimas décadas têm testemunhado uma transformação no conceito de desenvolvimento e na análise das variáveis que o influenciam. As especificidades regionais/locais passaram a ser entendidas como importantes aos processos de desenvolvimento, já que cada território responde de forma particular à diferentes estratégias e cria meios específicos para se desenvolver. Este artigo analisa a trajetória de um processo regional de desenvolvimento a partir das teorias institucionalista e schumpeteriana, com uma abordagem territorial. Compreende-se que elas fornecem importantes referenciais para análises de processos de desenvolvimento em âmbito local, pois consideram história, cultura, códigos de conduta, valores e técnicas como determinantes do desenvolvimento. No estudo se demonstra, a partir do caso da região Oeste Catarinense, que processos de desenvolvimento regionais podem ser analisados à luz destas teorias, como um encadeamento de dinâmicas organizativas e trajetórias tecnológicas locais, que se influenciam mutuamente e condicionam os caminhos possíveis ao desenvolvimento territorial.
\end{abstract}

Palavras-chave: Instituições. Inovações. Desenvolvimento. Região.

\begin{abstract}
The last decades witnessed a transformation of the concept of development and of the analysis of its explanatory variables. Regional/local specificities became important aspects of development processes since each territory reacts differently to different strategies and creates specific solutions for its development. This article analyzes the path of a regional development process from the perspective of the institutional, schumpeterian and territorial approach theories. They provide important references to analyze development processes at the local level, as they consider history, culture, behavior codes, values and techniques as determinants of development. The study builds on Santa Catarina's Western region case and shows that regional development processes can be analyzed with the support of these theories as a chain of organizational dynamics and local technological trajectories that influence each other and determine the possible courses of territorial development.
\end{abstract}

Keywords: Institutions. Innovation. Development. Region.

\section{Introdução}

Desde seu nascimento no século XVII, a ciência econômica desconsiderou (salvo raras exceções) o papel desempenhado pelas instituições, tecnologia e especificidades regionais. Nos modelos de crescimento neoclássicos, as instituições 
são apresentadas como variáveis exógenas, a tecnologia é tida como uma variável estática e, uma vez que estes modelos pretendiam-se universalmente aplicáveis, está implícita a desconsideração de características locais como variável importante no processo de desenvolvimento.

Porém, nas últimas décadas, observou-se uma modificação no conceito de desenvolvimento. Este se tornou mais abrangente e intimamente relacionado à aspectos de sustentabilidade econômica, social e ambiental. Além disso, as características locais passaram a ser entendidas como variáveis determinantes dos processos de desenvolvimento. O território, com seus atores, suas redes, suas instituições, suas técnicas e sua história, responde de forma particular e específica à diferentes estratégias de desenvolvimento e muitas vezes cria seus próprios meios de se desenvolver e superar as crises que podem surgir ao longo deste processo.

Duas variáveis importantes para a análise do desenvolvimento em âmbito local/regional são as dinâmicas organizativas e as trajetórias tecnológicas. As dinâmicas organizativas representam a forma como os atores locais se articulam visando, de forma planejada ou não, atingir seus objetivos. As trajetórias tecnológicas dizem respeito à forma como as técnicas se alteram, ora surgindo descontinuamente, ora em carácter incremental à técnica anterior.

Considerando estas duas variáveis, este artigo analisa a contribuição de duas correntes de pensamento econômico e social que fornecem elementos para interpretá-las e, desta forma, repensar os processos de desenvolvimento em âmbito local/regional: a teoria institucionalista e a teoria schumpeteriana. Suas contribuições para análises de desenvolvimento em âmbito local/regional, e sua aplicação na região Oeste de Santa Catarina estão discutidas a seguir.

\section{Uma revisão teórica para analisar processos locais/regionais de desenvolvimento}

As teorias institucionalista e schumpeteriana contribuem sobremaneira para discutir e analisar processos de desenvolvimento regional. A primeira, pela ênfase dada às dinâmicas organizativas e a segunda, às trajetórias tecnológicas, ambas permitindo aplicar seus conceitos a processos de desenvolvimento local/regional. A revisão que segue abrange os principais aspectos destas teorias.

\subsection{A teoria (neo)institucionalista e as dinâmicas organizativas}

As dinâmicas organizativas representam a forma como os diversos atores sociais organizam-se para atingir seus objetivos, sendo uma importante variável nas análises de processos de desenvolvimento. Partindo da perspectiva que a teoria institucionalista considera a cultura, a história e as instituições como elementos essenciais na análise do processo de desenvolvimento, pode-se dizer que esta teoria fornece suporte teórico e analítico para a compreensão das dinâmicas organizativas de um determinado um território específico.

A teoria institucionalista de desenvolvimento pode ser dividida em duas correntes: o velho institucionalismo, cujo principal representante é Thorstein 
Veblen, e o neoinstitucionalismo (ou Nova Economia Institucional), na qual se destaca a obra de Douglass North.

Os primeiros institucionalistas visavam explicar eventos e transformações a partir da sua conexão com o território, ou seja, identificavam no território as razões da mudança. Segundo North (1992), um território possui diversas organizações, as quais podem ser: políticas (conselhos municipais, senado, agencias regulatórias); econômicas (empresas, acordos comerciais, propriedades rurais, cooperativas); sociais (igrejas, clubes, associações atléticas); e educacionais (escolas, faculdades). Para ele, a partir da contínua interação entre estas organizações ocorre a mudança institucional.

Conforme citam Arend e Cário (2004), esta corrente não pretendia construir um modelo geral de análise econômica, mas elaborar um instrumental que contribuísse para análises específicas, historicamente localizadas. Os autores ainda citam que as principais características desta corrente de pensamento são: ênfase nas relações de poder existentes na interação entre indivíduos de uma sociedade; a sociedade e a economia deixam de ser vistas como um sistema autorregulado; o processo histórico de mudança é o foco da análise institucionalista e leva em conta as especificidades de cada situação; e a economia é entendida como parte de um todo, a cultura, em evolução.

Assim, a mudança institucional ocorre de forma lenta e interligada à fatos históricos, trazendo o conceito de "dependência da trajetória", o qual determina que "fatos aleatórios e remotos no tempo tem uma influência destacada para a evolução institucional" (AREND E CÁRIO, 2004, p. 4).

Já a corrente de pensamento neoinstitucinalista pode ser dividida, conforme Hall e Taylor (1996), em três métodos de análise distintos: o institucionalismo histórico, o institucionalismo da escolha racional e o institucionalismo sociológico, os quais buscam explicar o papel desempenhado pelas instituições no processo de crescimento e desenvolvimento.

O método histórico define como instituições todos os procedimentos, protocolos, normas e convenções inerentes à estrutura organizacional de determinada comunidade. De forma geral, as instituições estão associadas à regras e convenções estabelecidas por organizações oficiais. Segundo Hall e Taylor (1996), algumas estratégias oriundas de um contexto institucional específico podem "fossilizar-se" ao longo do tempo e desta forma acabam perpetuando-se em certo território.

Outro objeto de análise do institucionalismo histórico são as relações de poder assimétricas, as quais dividem o poder de forma desigual entre os diversos grupos sociais. Esta ótica assume que as instituições políticas estruturam certas categorias de interesse que estão mais suscetíveis de serem representadas nos processos de decisão.

Os teóricos do institucionalismo histórico rejeitam a hipótese tradicional de que as mesmas estratégias produzem os mesmos resultados, independentemente da região aonde são aplicadas. Defendem a hipótese de que o desenvolvimento pode ser causado por fatores que se encontram diferenciados em cada localidade, tendo propriedades herdadas do passado e evoluindo de forma dependente da 
trajetória já percorrida (HALL E TAYLOR, 1996).

Os autores citam que esta trajetória geralmente ocorre com períodos de "continuidade", algumas vezes interrompidos por "situações críticas", que podem ser crises econômicas ou conflitos militares, por exemplo. Nas ocasiões de situações críticas, mudanças institucionais importantes ocorrem e o rumo geralmente é alterado, conduzindo o desenvolvimento por um novo trajeto.

O segundo método de análise do neoinstitucionalismo, de acordo com Hall e Taylor (1996), refere-se a corrente da escolha racional. Os teóricos deste método consideram que os indivíduos sempre buscam maximizar as suas preferências, o que, algumas vezes, pode gerar um resultado diferente do que seria considerado ideal para a coletividade, gerando impactos adversos sobre o bem estar comum. Estes conflitos entre os objetivos individuais e os da sociedade ocorrem, de acordo com esta teoria, pela ausência de arranjos institucionais eficientes, os quais permitiriam que aos atores preferissem adotar estratégias benéficas à coletividade.

O terceiro método de análise citado por Hall e Taylor (1996) é o neoinstitucionalismo sociológico. Os pensadores desta corrente apresentam uma visão mais global do termo instituições, pois consideram que as instituições, além de um conjunto de regras, procedimentos e normas formais, são compostas por um "sistema de símbolos, esquemas cognitivos e modelos morais que fornecem 'padrões de significação' que guiam a ação humana" (HALL E TAYLOR, 1996, p. 209).

Além disso, os institucionalistas sociológicos defendem que determinadas práticas institucionais são adotadas pela legitimidade social e pelo valor cultural que fornecem aos seus adeptos. Isto significa que certas modificações nas práticas institucionais não se devem exclusivamente a uma escolha racional visando maximização e eficiência, mas sim a uma adaptação à mudanças no ambiente cultural. (HALL E TAYLOR, 1996, p. 211).

Pode-se dizer que as instituições influenciam a ação dos indivíduos, gerando determinadas dinâmicas organizativas e, por outro lado, as dinâmicas organizativas dos atores sociais também acabam por moldar novas instituições, o que gera a mudança institucional nos processos de desenvolvimento.

Desta forma, a importância desta teoria na análise do desenvolvimento em territórios específicos consiste em considerar as dinâmicas organizativas (influenciadas pelas instituições, pela história, pelos como costumes, hábitos, cultura e disponibilidade de recursos naturais) como fatores condicionantes da trajetória do desenvolvimento e seus resultados.

As dinâmicas organizativas se constituem diferentemente, conforme cada contexto territorial, articuladas a processos tecnológicos marcados por trajetórias próprias, mais ou menos dependentes da história de cada território.

\subsection{A teoria (neo)schumpeteriana e as trajetórias tecnológicas}

A teoria schumpeteriana e sua vertente neoschumpeteriana incorporam a variável tecnologia em suas análises sobre processos de desenvolvimento, e 
acreditam que a mudança tecnológica é o motor destes processos.

Para a teoria schumpeteriana, o desenvolvimento deve ser analisado por mudanças na vida econômica que se processam na própria esfera do sistema:

O desenvolvimento, no sentido em que o tomamos, é um fenômeno distinto, inteiramente estranho ao que pode ser observado no fluxo circular ou na tendência para o equilíbrio. É uma mudança espontânea e descontínua nos canais do fluxo, perturbação ao equilíbrio, que altera e desloca para sempre o estado de equilíbrio previamente existente (SCHUMPETER, 1988, p. 47).

Desta forma, o verdadeiro objeto de estudo da teoria schumpeteriana é a mudança econômica, a qual é causada, principalmente, pela inovação. É por este motivo que o processo de desenvolvimento econômico para Schumpeter têm no surgimento de novas tecnologias a sua principal variável analítica.

Para o autor, a inovação é aquela que rompe com o equilíbrio anterior do sistema e que aparece de forma descontínua. Uma inovação pode ocorrer a partir da introdução de um novo bem no sistema; introdução de um novo método de produção; abertura/exploração de um novo mercado; conquista de uma nova fonte de oferta de matéria-prima; ou o estabelecimento de uma forma diferente de organização industrial (SCHUMPETER, 1988, p. 48).

Conforme Schumpeter (1988), a produção de novos bens, ou qualquer outro tipo de inovação, ocasiona o desaparecimento dos bens/métodos antigos, determinando um processo de "destruição criadora". Este processo acontece quando há o aparecimento de novas mercadorias que substituem outras, ou quando novos processos produtivos acabam tornando-se dominantes em relação a outros.

Já no enfoque (neo)schumpeteriano, a técnica pode ser vista como o conjunto de rotinas de uma sociedade, podendo adaptar-se de acordo com a necessidade. A forma como ocorre uma mudança tecnológica ao longo do tempo se traduz no conceito de trajetória tecnológica, semelhante ao conceito institucionalista de dependência da trajetória. A trajetória tecnológica se refere à forma como as inovações se encadeiam entre si e dão continuidade a um determinado padrão de desenvolvimento, pois, conforme Furtado (2001, p. 258) "o campo das opções tecnológicas num determinado momento estaria condicionado por opções feitas em períodos anteriores". Assim, a trajetória tecnológica apresentaria um caráter incremental, onde a tecnologia evolui de forma dependente das opções anteriores.

Desta forma, tanto a visão de schumpeteriana na análise do desenvolvimento a partir de inovações tecnológicas descontínuas, quanto a visão neoschumpeteriana sobre o caráter dependente e incremental do processo de inovação tecnológica, fornecem importantes elementos para a compreensão do desenvolvimento regional e seus impactos econômicos, sociais e ambientais. 


\section{O desenvolvimento da região Oeste Catarinense: atores, dinâmicas e trajetórias}

Partindo de uma abordagem territorial e tendo como referência básica um estudo histórico realizado em documentos, livros e jornais sobre a região, é possível expor o desenvolvimento do Oeste Catarinense como um processo de encadeamento de dinâmicas organizativas e trajetórias tecnológicas, baseando-se nas teorias (neo)institucionalista e (neo)schumpeteriana.

\subsection{Descrição geral de características socioeconômicas regionais}

A região Oeste Catarinense abrange uma área de 27.303,5 mil quilômetros quadrados e possui uma população aproximada de 1,06 milhões de habitantes (IBGE, 2010).

A agricultura e a pecuária, aliadas às agroindústrias de pequenos animais, são as principais atividades econômicas da região. O setor primário da economia foi historicamente importante para o crescimento e dinamismo econômico do Oeste Catarinense. De uma agricultura de subsistência nos primórdios da ocupação regional, passando pela agricultura familiar diversificada voltada para o mercado, até $\mathrm{o}$ nascimento das agroindústrias e cooperativas, pode-se dizer que, historicamente, o setor agropecuário foi o motor do crescimento deste território.

Denardin e Sulzbach (2006, p. 5), citam que "o setor secundário, por seu turno, é dominado pelas indústrias agroalimentares e, por fim, as atividades comerciais e de serviços estão direta ou indiretamente ligadas ao setor agropecuário".

O complexo agroindustrial de carnes suínas e de aves da região é um dos maiores do Brasil, sendo também responsável por grande parte das exportações. Foi na região Oeste Catarinense que nasceram grandes empresas agroalimentares, tais como a Sadia, Perdigão, Seara, Chapecó (atualmente extinta) e a Cooperativa Aurora (MIOR, 2005). Com base nestes dados observa-se que este território desenvolveu-se apoiado no setor agropecuário e sendo assim, pode-se caracterizálo como um território predominantemente rural ${ }^{1}$.

A região tem como uma de suas principais características a predominância da agricultura familiar, sendo que tal característica decorre, principalmente, do processo de colonização regional iniciado nos anos de 1920. A agricultura desenvolvida pela mão-de-obra familiar desempenhou papel fundamental no processo de desenvolvimento do Oeste Catarinense.

A agricultura familiar representa $95 \%$ dos estabelecimentos rurais da região (MIOR, 2005). Historicamente, a produção agropecuária familiar baseou-se em culturas diversificadas, incluindo desde milho, arroz e feijão, até a criação de animais de serviço e de consumo, como suínos e aves. Posteriormente, ocorreu um

\footnotetext{
${ }^{1}$ Para Rover (2007) a região em estudo pode ser identificada como predominantemente rural, por conta da representatividade da atividade agropecuária para a região, apesar de alguns municípios apresentarem uma densidade populacional mais condizente com regiões urbanas.
} 
processo de integração dos agricultores familiares com as agroindústrias, fato que acabou determinando a exclusão de diversos produtores. A agricultura familiar entrou em crise no final dos anos 80 e a partir de então, foi o cerne de diversos movimentos sociais que originaram-se no campo. Ultimamente, esta categoria social vem buscando novas estratégias de desenvolvimento, alternativas ao sistema hegemônico implantado pelas agroindústrias. A agricultura familiar é a base social e econômica do processo de desenvolvimento do Oeste Catarinense, ora sendo protagonista de transformações, ora adaptando-se à mudanças exógenas.

Embora algumas vezes possa, à primeira vista, transmitir uma imagem de riqueza econômica e progresso, o desenvolvimento da região Oeste Catarinense foi marcado por profundas transformações que adentraram o campo social, econômico e ambiental. A seguir, apresenta-se uma análise do processo histórico de desenvolvimento regional, a partir da teoria institucionalista e schumpteriana, passando por 04 períodos: o primeiro abrange os anos anteriores à colonização ${ }^{2}$, a qual tem como marco de origem a década de 1920; o segundo, compreende os anos de 1920 até os 1960, período no qual se desenvolveu a agricultura familiar e surgiram as primeiras agroindústrias regionais; o terceiro, dos anos de 1970 aos de 1990, tem como principal marca a reestruturação e modernização agroindustrial na região; e o último, a partir dos anos de 1990 até os dias atuais, trata principalmente de duas crises, da agricultura familiar e a crise ambiental, bem como das alternativas que delas emergiram.

\subsection{O desenvolvimento regional como processo de encadeamento de dinâmicas organizativas e trajetórias tecnológicas}

Analisando-se o processo de desenvolvimento do Oeste catarinense a partir da teoria institucionalista e schumpteriana, pode-se afirmar que este processo histórico deu-se em função de dinâmicas organizativas e trajetórias tecnológicas diversas, que substituíram-se ou sobrepujaram-se em forma de movimentos ou processos hegemônicos e periféricos ${ }^{3}$.

Neste processo, as dinâmicas organizativas e as trajetórias tecnológicas modificaram-se ao longo do tempo, ora adaptando-se à transformações e demandas exógenas, ora elas mesmas influenciando e impulsionando modificações no rumo do desenvolvimento regional. A Figura 1 é um quadro síntese que busca mostrar esta dinâmica histórica.

Em um primeiro momento, anterior ao início da colonização, a região era ocupada por indígenas e caboclos. A dinâmica organizativa e trajetória tecnológica destes primeiros habitantes era baseada na agricultura de subsistência. Segundo

\footnotetext{
${ }^{2}$ Neste artigo, entende-se como colonização a chegada de imigrantes, principalmente descendentes de italianos e alemães, a partir do início da década de 1920, vindos do Rio Grande do Sul, para povoar mais densamente o Oeste Catarinense, agenciados por empresas colonizadoras.

${ }_{3}$ Como movimentos hegemônicos, entendem-se aqueles que por alguma razão tornam-se dominantes aos demais, impondo formas organizativas e tecnológicas que Ihes convém. Já os movimentos periféricos, são aqueles que situam-se à margem do movimento hegemônico, coexistindo e buscando alternativas para manterem-se ativos ou submergindo aos requisitos do movimento hegemônico.
} 
Breves (1985), a tecnologia adotada era o cultivo sucessivo de novas áreas: após o plantio e colheita de uma determinada área de terra, ocupavam outra para o novo plantio. O sistema de cultivo era a derrubada das matas, queima e plantio nas cinzas (agricultura de coivara) (BREVES, 1985). Este processo gerou impactos ambientais que, por não serem concentrados e em grande escala, permitiram a recuperação dos ecossistemas.

Considerando que características como a cultura, os valores e a história são importantes fatores que determinam a dinâmica organizativa, pode-se afirmar que a agricultura de coivara era fruto da cultura e do domínio tecnológico dos habitantes da região na época. Nem indígenas, nem caboclos tinham pretensões capitalistas, como a posse da terra e a geração de excedente agrícola. Aliás, mesmo se tivessem, pode-se afirmar que iriam defrontar-se com as especificidades da região, principalmente no que se refere às características do solo, relevo, disponibilidade de recursos naturais e limitado acesso aos mercados. Tais especificidades regionais ditaram a principal dinâmica organizativa da época, baseada na agricultura de subsistência, da mesma forma que as características desta agricultura foram influenciadas pelos costumes, hábitos e tradições da população local.

O surgimento da colonização, no início dos anos 1920, capitaneada pelas empresas colonizadoras com o suporte do Estado, destaca-se como primeiro grande movimento hegemônico na região, o qual gerou inúmeros conflitos e colocou à margem de sua dinâmica as etnias caboclas e indígenas.

Conforme a teoria institucionalista, em certas ocasiões as instituições podem gerar relações de poder assimétricas, na qual certos grupos de interesse têm acesso desproporcional ao processo decisório. No Oeste Catarinense, o Estado decidiu repassar áreas de terra para empresas colonizadoras, representadas por grandes empresários e políticos, deixando caboclos e indígenas à margem do processo. Se o objetivo do Estado era colonizar estas terras, o objetivo das colonizadoras era o lucro com a venda das terras (BAVARESCO, 2005).

O início da colonização pode ser tomado, de acordo com o neoinstitucionalismo, como uma "situação crítica" no processo de desenvolvimento regional, a partir do qual ocorrem mudanças institucionais importantes, que conduzem o desenvolvimento por uma nova trajetória. Em termos schumpeterianos, a colonização do Oeste pode ser vista como um rompimento na trajetória tecnológica existente, até então desenvolvida pelos caboclos e índios, a partir de uma inovação: a transformação da terra em propriedade privada ${ }^{4}$, conforme citado por Auras (1984). Esta inovação apareceu de forma descontínua (independente da trajetória anterior), alterando e deslocando para sempre o estado de equilíbrio prévio, sendo o início do que Schumpeter chama de boom econômico. Ou ainda, conforme a teoria schumpeteriana, a colonização pode ser tida como uma forma de "destruição criadora", que, ao mesmo tempo em que criou uma nova trajetória, causou o desaparecimento das formas de produção antigas.

\footnotetext{
${ }^{4}$ Esta transformação foi uma decorrência da Lei de Terras, de 1850, que em seu artigo $1^{\circ}$, declara que "Ficam proibidas as aquisições de terras devolutas por outro titulo que não seja o de compra" (BRASIL, 1850)
} 


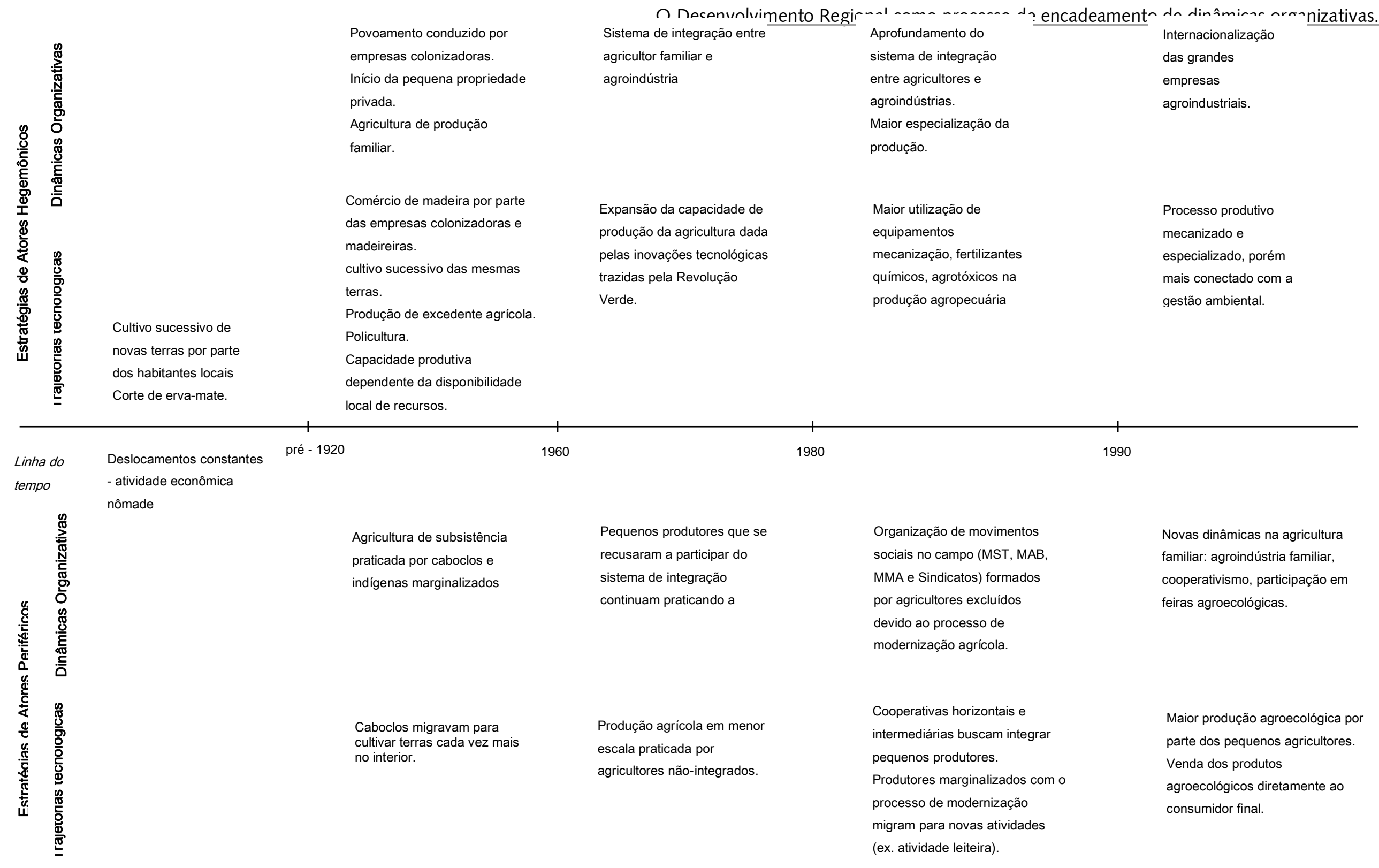

Figura 1. Resumo histórico de dinâmicas organizativas e trajetórias tecnológicas no Oeste Catarinense Fonte: elaborado pelos autores. 
A colonização colocou os habitantes pioneiros como sujeitos marginais, enquanto a cultura dos imigrantes, vindos principalmente do Rio Grande do Sul, impôs-se como uma forma de organização superior. Uma nova trajetória tecnológica surgiu, baseada na mão de obra familiar do colono migrante com a geração de excedente agrícola. De acordo com Poli (2008), a adoção da policultura deveu-se, além da continuidade cultural com práticas trazidas do Rio Grande do Sul, à uma adaptação a duas principais especificidades regionais: a divisão do território em pequenas propriedades quando da venda das terras por parte das empresas colonizadoras e a ausência de um mercado estruturado capaz de oferecer aos imigrantes os diversos produtos para sua subsistência, obrigandoos a produzi-los na própria propriedade.

Assim, adaptando-se às especificidades regionais e agregando valores de sua cultura, os imigrantes iniciaram na região Oeste Catarinense o cultivo de diversos produtos, como arroz, feijão, trigo, batata, mandioca e milho, além da criação de suínos para absorver o excedente da plantação de milho (POLI, 2008). O início da criação de suínos pode ser visto, conforme a abordagem neoschumpeteriana, como um processo tecnológico incremental ao cultivo de milho, representando uma adaptação técnica incremental àquela existente, revelando um carácter de "dependência da trajetória".

As pequenas vilas e povoados eram isoladas do restante do Estado, o que por vezes colocava o colono migrante em situações difíceis. Para responder a este contexto, originou-se certa densidade institucional, composta por laços de confiança, reciprocidade e cooperação, representados pelas relações de coletividade e espírito comunitário entre os primeiros colonos, já que, distantes, contavam apenas com a ajuda uns dos outros (BAVARESCO, 2005).

Apesar de, neste período, já se iniciar o desenvolvimento de uma atividade agrícola com pequena produção de excedente, é a atividade madeireira o motor do desenvolvimento econômico regional até a década de 1940 (BAVARESCO, 2005). A existência de uma vasta mata nativa com madeiras nobres fez expandir esta atividade ao longo do período da colonização. A madeira era exportada principalmente para a Argentina através de balsas no rio Uruguai. Dada a inexistência de políticas de preservação ambiental, esta atividade desenvolveu-se gerando um grande dano ambiental para a região, que atualmente possui aproximadamente apenas 9,17\% da mata original, conforme dados da Fundação SOS Mata Atlântica (2008). A ausência de um arranjo institucional eficiente permitiu que as empresas madeireiras, ao buscar maximizar seus interesses, gerassem, no decorrer do tempo, um subótimo para a sociedade. Este subótimo acontece principalmente pela ausência de arranjos institucionais eficientes, composto por organismos capazes de proteger o meio ambiente e incentivar os atores sociais a adotar linhas de ação com benefícios coletivos, como explicado pela teoria institucionalista.

Apesar dos impactos ambientais adversos, foi ao redor das empresas madeireiras que se desenvolveram as primeiras vilas e comunidades (BAVARESCO, 2005). Porém, a continuidade da atividade madeireira dependia, além da existência da matéria-prima, do ritmo das cheias do rio Uruguai, já que a madeira era transportada via balsa. No final da década de 1940, houve um período de 
seca, que impediu o comércio da madeira, que já estava ficando escassa devido à intensa exploração, o que colocou a atividade em crise (VOZ DE CHAPECÓ, 1946). A teoria neoschumpeteriana nos diz que o surgimento de algum tipo de problema, leva a uma adaptação da trajetória tecnológica. Na medida em que a atividade madeireira entrou em crise, as atividades econômicas na região diversificaram-se, e a produção agrícola diversificada passou a ganhar mais espaço.

A produção agropecuária praticada pelo colono imigrante tem dinâmicas organizativas e trajetórias tecnológicas bastante distintas daquela do período anterior a colonização. Em termos sociais, as dinâmicas organizativas são em grande parte influenciadas pelas escolas e, principalmente, pela Igreja, que estabelece espaços comunicativos nas comunidades, incentivando a mobilização e organização de pequenos produtores (POLI, 2008). As dinâmicas organizativas econômicas, para além da extração madeireira, eram representadas principalmente pelo sistema de cultivo calcado na pequena propriedade, na produção familiar e na policultura. As trajetórias tecnólogicas estavam em grande parte controladas pelos agricultores, já que o sistema de produção dependia basicamente da sua disponibilidade de recursos e de seu conhecimento sobre os ciclos agrícolas, as leis da natureza, as técnicas de seleção e conservação de sementes, etc (PRESTES et al, 2012). Estes conhecimentos são, conforme o velho institucionalismo, culturas e rotinas que se institucionalizaram ao longo do tempo, e na época, determinaram a forma de ação dos atores.

A partir deste contexto, o comércio de produtos agropecuários apareceu como uma dinâmica organizativa que teve na figura do comerciante um de seus atores principais. Os comerciantes eram, em geral, pessoas vindas do Rio Grande do Sul, com alguma experiência prévia em comercialização, ou seja, o comércio era algo já institucionalizado em sua cultura. Configurava-se como o centro dos negócios da comunidade, através do qual o agricultor trocava o excedente da colônia por produtos que não possuía ou, mais raramente, por dinheiro (BAVARESCO, 2005). Representou assim, outra inovação tecnológica nos termos schumpeterianos, ao introduzir as dinâmicas comerciais na região.

Relações de poder assimétricas também são verificadas na relação entre o agricultor e o comerciante. De acordo com Bavaresco (2005), por parte do pequeno produtor, o comerciante era visto como uma pessoa mais entendida, mais sábia. Com a confiança à ele depositada, o comerciante passou, muitas vezes, a definir os preços dos produtos intermediados em seu comércio, bem como a ditar as regras na sociedade. Esta dinâmica acabou gerando uma certa dependência do colono em relação ao comerciante, já que era por meio dele que o colono repassava seu excedente.

A figura do comerciante surge como dominante à cultura do pequeno produtor rural e é dela que surgirá o próximo movimento hegemônico, quando, a partir da década de 1940, os comerciantes regionais começaram a instalar as primeiras agroindústrias na região.

O surgimento destas agroindústrias também remete à uma "dependência da trajetória", pois foi devido ao acúmulo de capital por parte das atividades comerciais, que os referidos comerciantes tiveram capacidade financeira para iniciarem os empreendimentos. 
Ao instalarem-se no Oeste Catarinense, as agroindústrias encontraram grandes fontes de matéria-prima, conforme cita Testa et al (1996). Isto porque a produção de suínos já se encontrava relativamente desenvolvida. Mais uma vez, especificidades regionais influenciaram na técnica e na produção escolhida. Dado a dificuldade de acesso aos mercados, a criação de porcos foi preferível à produção de grãos, por serem algo que "se movia", evitando assim, maiores dificuldades no transporte (GRANDO, 2001 apud BAVARESCO, 2005). Quanto às técnicas de criação, os animais eram criados soltos e alimentados basicamente com milho, abóbora e batata.

Com o objetivo de manter estabilidade no abastecimento de suínos, as agroindústrias iniciaram um sistema de integração com os pequenos produtores, fato que iria acabar modificando tanto as dinâmicas organizativas como as trajetórias tecnológicas locais.

A tecnologia até então praticada apresentou um rompimento de sua trajetória, já que, no sistema de integração, as agroindústrias fornecem aos produtores os insumos, os medicamentos, vacinas e ração, e comprometem-se em adquirir a produção, após descontar os produtos fornecidos (MIOR, 2005). Em decorrência desta mudança na trajetória, identifica-se também uma mudança nas dinâmicas organizativas, verificada principalmente nas relações entre as famílias de pequenos agricultores que, agora inseridas no sistema capitalista de produção, abandonaram, em grande parte, suas relações de cooperação, troca e empréstimos entre os colonos, hábitos que foram importantes nos primórdios da colonização (BAVARESCO, 2005).

$\mathrm{Na}$ década de 1950, com o crescimento dos mercados consumidores no Brasil, surgiu uma série de instituições e programas que visavam incentivar e ampliar a produção, como, por exemplo, a fundação da ACARESC (Associação de Crédito e Assistência Rural de Santa Catarina), que prestava assessoria técnica aos produtores, como também a expansão do crédito agrícola e diversas políticas de fomento às agroindústrias da região. Esta, além do crédito que começava a se disponibilizar, foi a principal ação do Estado para iniciar o processo de modernização do Oeste Catarinense (ROVER, 2010).

Neste contexto, o processo de modernização agrícola trazido pela "revolução verde" no início dos anos de 1970 surgiu como uma nova "situação crítica" no processo de desenvolvimento do Oeste, ou ainda, de acordo com Schumpeter, esta "revolução" introduziu novas técnicas e formas de produção que surgiram como uma inovação, que deslocou novamente o estado de equilíbrio previamente existente.

Uma nova trajetória tecnológica iniciou-se. Se até 1970, os pequenos produtores tinham relativo controle de sua produção, dos insumos utilizados, etc, este fato mudou com as novas técnicas trazidas pela "revolução verde", tais como a mecanização, os fertilizantes químicos, os agrotóxicos, etc. Além disso, o sistema de integração aprofundou-se e tornou o agricultor mais dependente da agroindústria. A trajetória tecnológica mudou principalmente no sentido de que, se antes os limites de produção eram dados pelas leis da natureza e o seu conhecimento e uso pelos agricultores, nesta nova fase, as novas tecnologias ampliaram a capacidade de produção e diminuíram a dependência em relação aos 
recursos naturais (PRESTES et al, 2012).

Do ponto de vista da teoria institucionalista, esta mudança nas rotinas técnicas e na dinâmica organizativa pode ser vista não apenas como uma escolha racional pela maximização de lucros por parte das agroindústrias, mas como uma adaptação à mudanças no ambiente político-cultural, já que na época o incentivo à industrialização fazia parte da própria política do Estado Brasileiro.

Na década de 1980, com a crise da dívida externa nacional e com a redução do crédito e da capacidade do Estado para financiar a modernização, país a fora, as agroindústrias tiveram que reordenar sua trajetória, buscando maior produtividade e competitividade. Isto as levou à uma maior seleção e exclusão de pequenos produtores, gerando impactos sociais negativos, sendo responsável pelo início da crise da agricultura regional (MIOR, 2005).

Além destes impactos sociais, os impactos ambientais também foram negativos, principalmente pela sobreutilização de recursos naturais como o solo, pela utilização de fertilizantes químicos, agrotóxicos, além da poluição das águas por dejetos de suínos, principalmente (GUIVANT e MIRANDA, 1999).

A industrialização e a modernização, capitaneadas pelas agroindústrias, podem ser vistas como uma trajetória tecnológica dominante, que apesar de ter gerado impactos econômicos positivos para a região como um todo, também produziu diversos impactos negativos do ponto de vista social e ambiental.

Entretanto, conforme o velho institucionalismo, os indivíduos não são entes socialmente passivos ou inertes, mas sim, reagem às mudanças em seu ambiente. $\mathrm{Na}$ região Oeste, isto pode ser exemplificado nas estratégias de movimentos periféricos que pressionaram e tem pressionado para o surgimento de novas dinâmicas organizativas e trajetórias tecnológicas na região, que lutam principalmente contra o movimento hegemônico e buscam alternativas para a reprodução da unidade familiar de produção.

Dentre estes movimentos, destacam-se o Movimento dos Sem Terra (MST), o Movimento das Mulheres Agricultoras (MMA) e o Movimento dos Atingidos por Barragens ( $M A B)$, todos surgidos de organizações de pequenos agricultores que se encontravam em situação precária na década de 1980, com os efeitos sociais perversos da modernização. Com o apoio da igreja, estes movimentos organizaram-se contra a lógica da modernização como estratégia de desenvolvimento hegemônica, e contra a exclusão socioeconômica de pequenos produtores (POLI, 2008).

Este fato nos remete ao conceito do processo evolucionário da teoria institucionalista. A modernização, como trajetória tecnológica dominante, trouxe maior crescimento econômico, mas, conforme a teoria institucional, o ambiente econômico envolve disputas, antagonismos, conflitos e incertezas. Estes conflitos se deram principalmente no campo social, com a exclusão de centenas de produtores que não puderam acompanhar o processo modernizante. E foi exatamente destes atores excluídos que surgiram novas instituições, propondo novas dinâmicas organizativas, como é o caso dos movimentos sociais citados. Em termos teóricos, pode-se dizer que as mudanças tecnológicas levaram ao surgimento de novas dinâmicas organizativas e institucionais. 
Paralelo aos movimentos sociais e muitas vezes incentivados por estes, além de influenciadas pelo ambiente como um todo, a partir dos anos 1990 surgem diversas formas alternativas de produção e novas dinâmicas organizativas por parte dos agricultores familiares.

A bovinocultura de leite, por exemplo, passou, em muitas propriedades, de atividade complementar para atividade principal (MIOR, 2005). O surgimento de pequenas agroindústrias familiares nas propriedades rurais também representa uma nova dinâmica organizativa e trajetória tecnológica, a partir da revalorização do produto colonial. Este produto reflete os princípios da teoria institucionalista, pois está intimamente relacionado com os valores e a cultura das famílias produtoras, especialmente no que concerne a sua cultura e gastronomia típica.

A produção agroecológica também foi uma alternativa tecnológica que adaptou-se à produção familiar. A não utilização de fertilizantes de síntese química e agrotóxicos torna o agricultor menos dependente de insumos industrializados, além de, exatamente por não utilizar agrotóxicos ou fertilizantes químicos demasiadamente, apresenta impactos ambientais menores (MARQUES e MELLO, 2009).

Neste contexto, o surgimento das Feiras de Produtos Coloniais e Agroecológicos configuram-se como um novo canal de comercialização, conforme citam Marques e Mello (2009) e por isso, sob a ótica deste estudo, representam uma nova combinação nos termos schumpeterianos, que impulsiona o crescimento a partir de mudanças de dentro da própria esfera econômica.

Além disso, o aparecimento de diversas organizações sociais, como as cooperativas de agricultura familiar e de crédito, os sindicatos e movimentos sociais no campo, as Secretarias de Desenvolvimento Regional, caracterizam a ampliação de um ambiente institucional propício à promoção do desenvolvimento local/regional, que tendem a facilitar o desenvolvimento.

Desta forma, pode-se observar que o processo de desenvolvimento da região Oeste Catarinense consiste em um encadeamento de dinâmicas organizativas e trajetórias tecnológicas. A agricultura de subsistência foi suplantada pela agricultura orientada para o mercado, apesar de não ter deixado de existir, mesmo que marginalizada. A acumulação de capital gerada por esta dinâmica organizativa propiciou o surgimento de agroindústrias. A dinâmica das agroindústrias tornou-se o novo movimento hegemônico, o qual foi marcado por mudanças tecnológicas importantes. Estas mudanças causaram impactos sociais e ambientais severos, o que incentivou o surgimento de movimentos de contraponto, levantados por grupos marginais ao processo hegemônico, os quais propõem novas dinâmicas organizativas e trajetórias tecnológicas para a organização social e produtiva na região.

\section{Considerações Finais}

O termo desenvolvimento, desde o surgimento da ciência econômica no século XVII, esteve associado ao crescimento econômico. Porém, nas últimas 
décadas, ocorreram importantes modificações nas formas de pensa-lo, assim como nas suas variáveis. Dentre as principais mudanças, está a análise das especificidades regionais como fatores determinantes dos resultados das estratégias de desenvolvimento.

A teoria institucionalista e schumpeteriana fornecem subsídios teóricos para analisar processos de desenvolvimento a partir de uma abordagem local. A primeira, por considerar a cultura, a história, os códigos de conduta de uma região, o que dá bons elementos para a análise das dinâmicas organizativas dos atores locais. A segunda, por analisar a forma como as tecnologias se transformam e se encadeiam, podendo assim explicar as trajetórias tecnológicas de um território específico.

No caso da região Oeste Catarinense, pode-se observar que a agricultura de subsistência foi substituída pela agricultura orientada para o mercado, o que se deu com o início da colonização. Este novo tipo de agricultura representou uma nova dinâmica organizativa, que permitiu uma maior acumulação de capital e propiciou o surgimento das agroindústrias. Estas, por sua vez, capitanearam um movimento hegemônico, o qual trouxe diversas mudanças tecnológicas. Estas mudanças dinamizaram o setor agroindustrial regional, mas também causaram impactos sociais e ambientais adversos. Visando enfrentar e amenizar estes impactos, emanam dos grupos sociais marginalizados, diversos movimentos de contraponto, os quais propõem dinâmicas organizativas e trajetórias tecnológicas mais sustentáveis econômica, social e ambientalmente. Estas dinâmicas e trajetórias emanam dos atores locais, mesmo que influenciados por processos extra locais, ao mesmo tempo em que estes atores são influenciados pelas dinâmicas e trajetórias que propõem, implementam ou até mesmo enfrentam.

Este estudo demonstrou, a partir do caso da região Oeste Catarinense, que processos de desenvolvimento regionais podem ser analisados como um encadeamento de dinâmicas organizativas e trajetórias tecnológicas locais, que se influenciam mutuamente e condicionam os caminhos possíveis ao desenvolvimento territorial.

\section{REFERÊNCIAS}

AREND, Marcelo; CÁRIO, Silvio A. F. Instituições, inovações e desenvolvimento econômico. Florianópolis, 2004.

AURAS, Marli. Guerra do Contestado: a organização da irmandade cabocla. Florianópolis: UFSC, 1984.

BAVARESCO, Paulo R. Ciclos econômicos regionais: modernização e empobrecimento no Extremo Oeste Catarinense. Chapecó: Argos, 2005.

BRASIL. LEI $\mathrm{n}^{\circ} 601$ de 18 de SETEMBRO DE 1850. Disponível em: www.planalto.gov.br. Acesso em: 02/04/2012.

BREVES, Wenceslau de S. O Chapecó que eu conheci. Revista do Instituto Histórico e Geográfico de Santa Catarina. Florianópolis. IHGSC. 3(6), 1985. 
DENARDIN, Valdir F.; SULZBACH, Mayra T. A agropecuária no oeste catarinense SC: é possível ser sustentável? Caxias do Sul: 2006. 26 p. Disponível em: <http://www.ecoeco.org.brf>. Acesso em: 26/09/2009.

FUNDAÇÃO SOS MATA ATLÂNTICA. Atlas dos remanescentes florestais da Mata Atlântica. São Paulo, 2008.

FURTADO, André. Opções tecnológicas e desenvolvimento do terceiro mundo. In: CAVALCANTI, Clóvis (Org.). Desenvolvimento e Natureza: estudos para uma sociedade sustentável. 3. ed. São Paulo: Cortez, 2001. 429 p.

GUIVANT, Júlia S.; MIRANDA, Cláudio. As duas caras de Jano: agroindústrias e agricultura familiar diante da questão ambiental. In: Cadernos de Ciência e Tecnologia. Brasília, $1999 . \quad$ Disponível em: < http://webnotes.sct.embrapa.br/pdf/cct/v16/cc16n304.pdf>. Acesso em: 27/08/2010.

HALL, Peter A.; TAYLOR, Rosemary C. R. As três versões do neo-institucionalismo. Political Studies, $1996 . \quad$ Disponível em: http://www.scielo.br/pdf/In/n58/a10n58.pdf. Acesso em: 05/12/2010.

INSTITUTO BRASILEIRO DE GEOGRAFIA E ESTATÍSTICA - IBGE. Censo Demográfico 2010. Disponível em: <http://www.ibge.gov.br>. Acesso em: $12 / 08 / 2011$.

MARQUES, Flávia C.; MELLO, Márcio A. Produção de novidades: "desvios" da agricultura familiar no Oeste de Santa Catarina. $4^{\circ}$ Congresso da Sociedade Brasileira de Economia, Administração e Sociologia Rural (SOBER). Porto Alegre, 2009.

MIOR, Luiz C. Agricultores familiares, agroindústrias e redes de desenvolvimento rural. Chapecó: Argos, 2005.

NORTH, Douglass. The new institutional economics and development. American Economist, 1992. Disponível em:<http://qed.econ.queensu.ca/pub/faculty/lloydellis/econ835/readings/north.pdf $>$. Acesso em: 02/06/2010.

POLI, Odilon. Leituras em movimentos sociais. 2 ed. rev. Chapecó: Argos, 2008.

PRESTES, Rosi M.; ROVER, Oscar J.; BERTO, James L. Representação social sobre um problema ambiental: o caso de suinocultores do sul do Brasil. VII Simpósio Nacional de Educação. Frederico Westphalen, RS, 2012.

ROVER, Oscar J. Gestão política e desenvolvimento na região Oeste de Santa Catarina. Cadernos do CEOM: políticas públicas, memórias e experiências. Ano 22, n. 30, 2010. 
ROVER, Oscar J. Redes de poder e governança local: análise da gestão políticoadministrativa em três fóruns de desenvolvimento com atuação na região Oeste de Santa Catarina. Tese de Doutorado (UFRGS), 2007.

SCHUMPETER, Joseph A. Teoria do desenvolvimento econômico: uma investigação sobre lucros, capital, crédito, juro e o ciclo econômico. São Paulo: Nova Cultural, 1988.

TESTA, Vilson M. O desenvolvimento sustentável do Oeste Catarinense (proposta para discussão). Florianópolis: EPAGRI, 1996. 247 p.

VOZ DE CHAPECÓ. Progresso. Chapecó, 11 de agosto de 1946.

Submetido em 19/11/2012

Aprovado em 20/07/2014

Sobre os autores

Bianca Cristina Aléssio

Graduação em Ciências Econômicas - Unochapecó. Mestrado em Ciências Ambientais Unochapecó.

Endereço: R. Marcolina da Silva, 47 E - Bairro: SAIC. CEP 89802-090 - Chapeco - SC - Brasil.

E-mail: biabia@unochapecó.edu.br

\section{Oscar José Rover}

Agrônomo, mestre em Sociologia Política e doutor em Desenvolvimento Rural. Porfessor Adjunto da Universidade Federal de Santa Cruz do Sul. Membro do Programa de Pós-Graduação em Agroecossistemas/UFSC.

Endereço: Rod. Admar Gonzaga, 1346, Itacorubi. CEP 88040900 - Florianópolis - SC - Brasil.

E-mail: oscar.rover@ufsc.br 